\title{
A REVIEW OF:
}

\section{CLARE JOHNSON (2013), FEMININITY, TIME AND FEMINIST ART. BASINGSTOKE AND NEW YORK: PALGRAVE MACMILLAN. PP. 173, ISBN 978-0-230-29848-4}

\author{
BARBARA FRANCHI \\ SCHOOL OF ENGLISH, UNIVERSTTY OF KENT
}

The role of women in making art and the agency of the overly-represented female body in artistic practices have been crucial debates in $20^{\text {th }}$ century Western feminism and beyond. In particular, it was in the wake of the second wave of feminism, with the emergence of poststructuralism and deconstruction, and the postmodern turn that critical assessments of the arts started claiming back female spaces and voices in the midst of a still largely patriarchal artistic scene.

In the final decades of the last century, pioneering contributions in the field emerged. Books such as Griselda Pollock's Vision and Difference: Femininity, Feminism and the History of Art (1980) and Lynda Nead's The Female Nude: Art, Obscenity and Sexuality (1992) analysed the role of women's bodies and their agencies in Western art from antiquity to the $20^{\text {th }}$ century. Importantly, they also created a genealogy of female presences in the arts, as models, muses and practitioners.

In the wake of these earlier publications, Clare Johnson's Femininity, Time and Feminist Art opens on the notion of time, although it challenges significantly the idea of generation posited by previous scholarship. In particular, Johnson's starting point is Julia Kristeva's 'Women's Time' and the two forms of temporality which the 1981 article associates to femininity: the repetitive time of 'cycles, gestation, the eternal recurrence of a biological rhythm' (Kristeva, 1981, p. 16), and the monumental, all-encompassing dimension of time. In this respect, Kristeva's definition of generations (of feminists), which Johnson productively appropriates in her book, 'implies less a chronology than a signifying space, a both corporeal and desiring mental space.' (p. 33). Similarly to Kristeva, Johnson sees different generations of feminist artists as not time-constrained, but instead, as a movement which is defined by non-linear temporality and goes beyond the concepts of intergenerational influence, appropriation and re-assessment of past ideas and practices.

Johnson's analysis of contemporary artistic practice alongside feminist movements does not have a chronological framework: rather, it shows how from the 1970s onwards, female artists contributed to the representation of gender, femininity and time while mutually informing one another and creating productive, cross-temporal interactions between artistic practices and feminism. So, from Tracey Emin's teenage memoir in the short film Why I Never Became a Dancer, to Vanessa Beecroft's and Sam Taylor-Johnson's representations of repetition and stasis, (in particular, with $v 629$ and David) Johnson traces a path from childhood, motherhood and female 
creativity, to a deconstruction of gender in contemporary artistic practice. Representing and questioning of temporality being the major criteria behind Johnson's structure, she effectively brings the reader from the representation of childhood traumas through memories (Emin) to creative challenges of the objectification and commerce of female bodies (Antin, Manchester, Wilke), from representations of female sexuality (Carolee Schneeman, Emin) to the stasis of powerful and queer mementi mori (Taylor-Johnson, Beecroft).

One of the strengths of this book is certainly its positioning of such diverse artists from the contemporary British and North American scene within a non-linear concept of generation of feminist practitioners, while not forgetting how the allegiance to the movement of the artists in question, as in the cases of Emin and Beecroft, is not always a given. In addition, unlike many other publications in the field, Johnson focuses exclusively on contemporary art practice, although many references to canonical representations of women and femininity in Western art (e.g. the trope of the Madonna or the female nude) are provided. So, instead of outlining a history of feminism and the visual arts, Johnson challenges linear temporality and adopts a Kristevian approach to time. She therefore reads the works by the 7 artists discussed in parallel to one another, as in mutual dialogue in spite of the temporal and contextual differences between the 1970s and the early years of the new millennium.

The best example in this respect is provided by Chapter 2, in which the author examines temporal complexity and the diversification of working and leisure time in two serial works: Eleanor Antin's Carving: A Traditional Sculpture (1972) and Elizabeth Manchester's All My Dresses with All My Shoes (2002). Not only does Johnson underline the influence of the former artist on the latter, in that both give a similar structure to their work to convey a feminist message against female objectification, but also to view the two pieces 'in the relational web of mutually constitutive meanings' (Johnson, 2013, p. 40).

Johnson's language is clear, accessible and compelling to both the academic scholar and the lay reader who is interested in contemporary art. It is not addressed specifically to an audience of experts, but its line of reasoning and the presence of images from the artworks and performances in question opens it, laudably, to the general public as well as the student and scholar of feminist movements and/or artistic practices. Also, the theoretical apparatus is strong, interesting and definitely convincing, as is Johnson's idea of a cross-time generation which defies 'monumental time' and 'linearity', in favour of a different assessment of femininity across time.

Unfortunately, however, the book does not provide a convincing definition of what feminism and its relation to femininity are, or even what feminism might include and what not - as the only comment close to the definition of feminism the author provides is that the boundaries between feminism and femininity are rather blurred.

Finally, although the book's structure is convincing and compellingly leads the reader across different artistic practices to a redefinition of gender and time (as Johnson appropriately concludes with David, a reassertion of masculinity through femininity, and therefore a redefinition of gender difference tout court), the book lacks a much-needed conclusion. The lack of a final chapter is rather surprising, given the thorough method of the author's argument throughout, therefore it is the more a pity that she provides none, be it a final statement or a set of unanswered questions to develop in future projects.

Nonetheless, through its accessible language and format, this book provides an original reading of a crucial issue in contemporary political and artistic debates, so it would definitely deserve to be not only in university libraries shelves, but also on the shelves of art gallery and museum bookshops. 


\section{References}

Kristeva, J. (1981). Women's Time. Signs, 7(1), 13-35.

Nead, L. (1992). The Female Nude: Art, Obscenity and Sexuality. London: Routledge.

Pollock, G. (Ed.). (1996). Generations and Geographies in the Visual Arts: Feminist Readings. London: Routledge. 